\title{
Memorial Pictures from 4th National Orthodontic Conference February 2014 Organized by Bangladesh Orthodontic Society
}
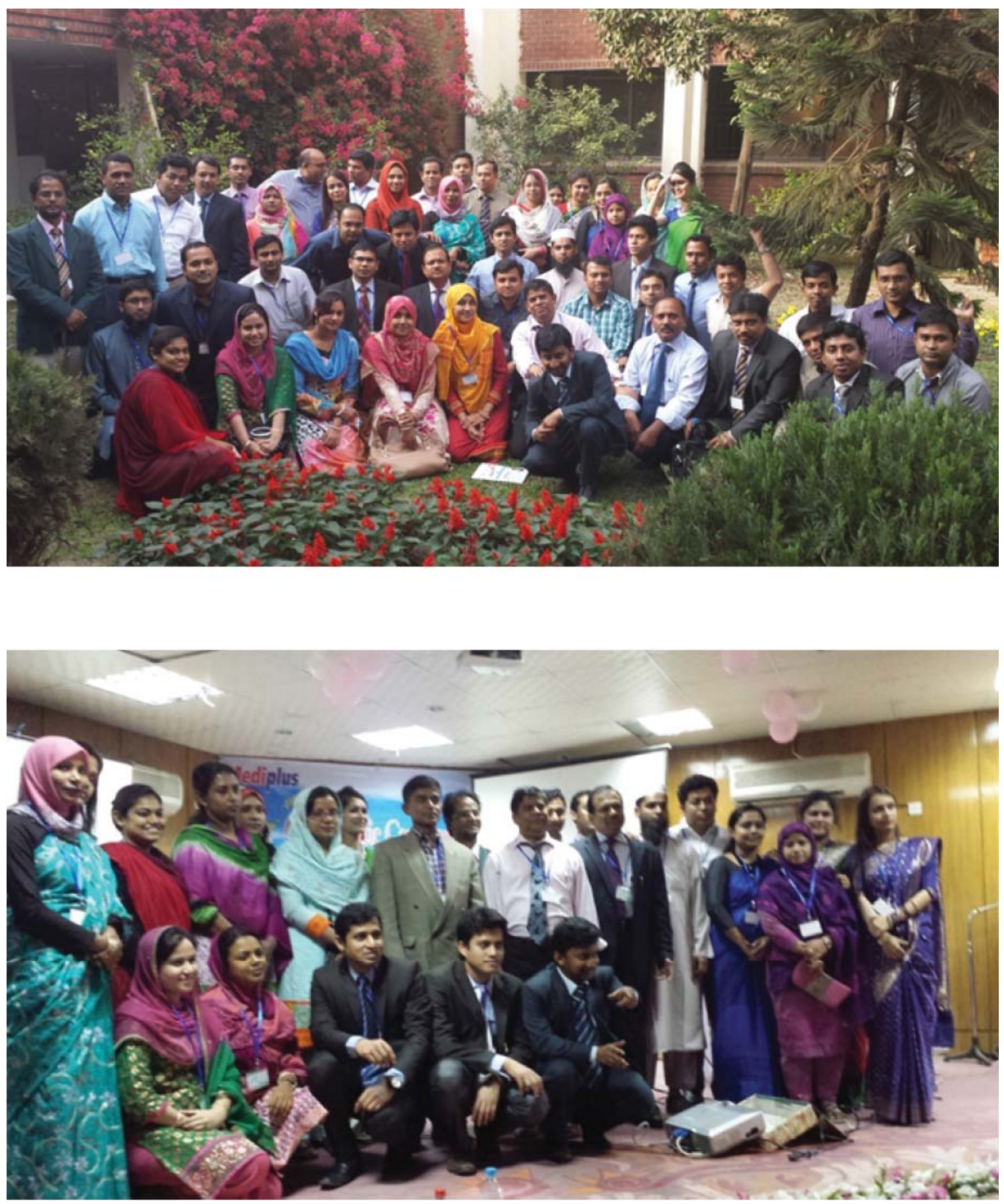


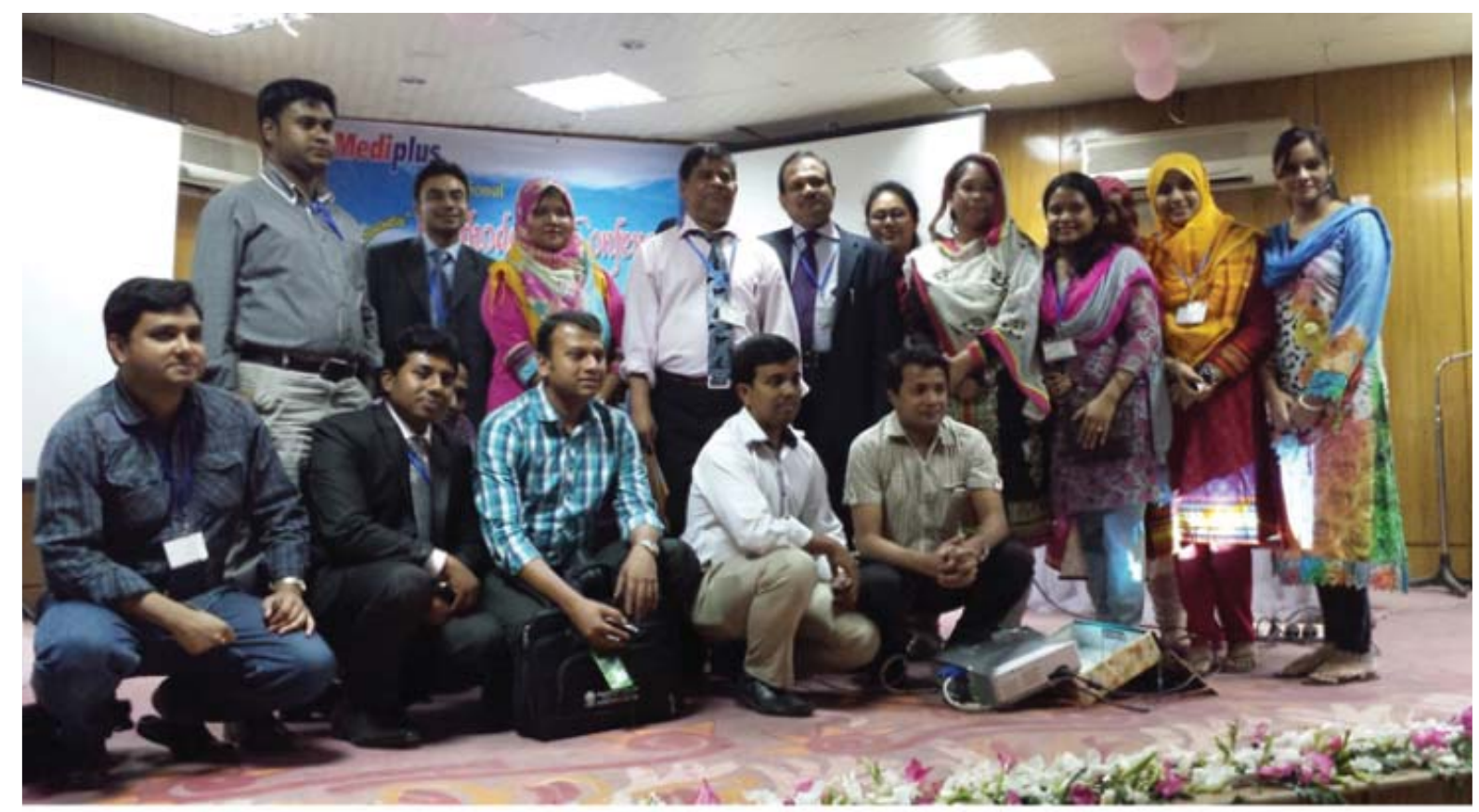

Memorial Pictures from 4th National Orthodontic Conference February 2014
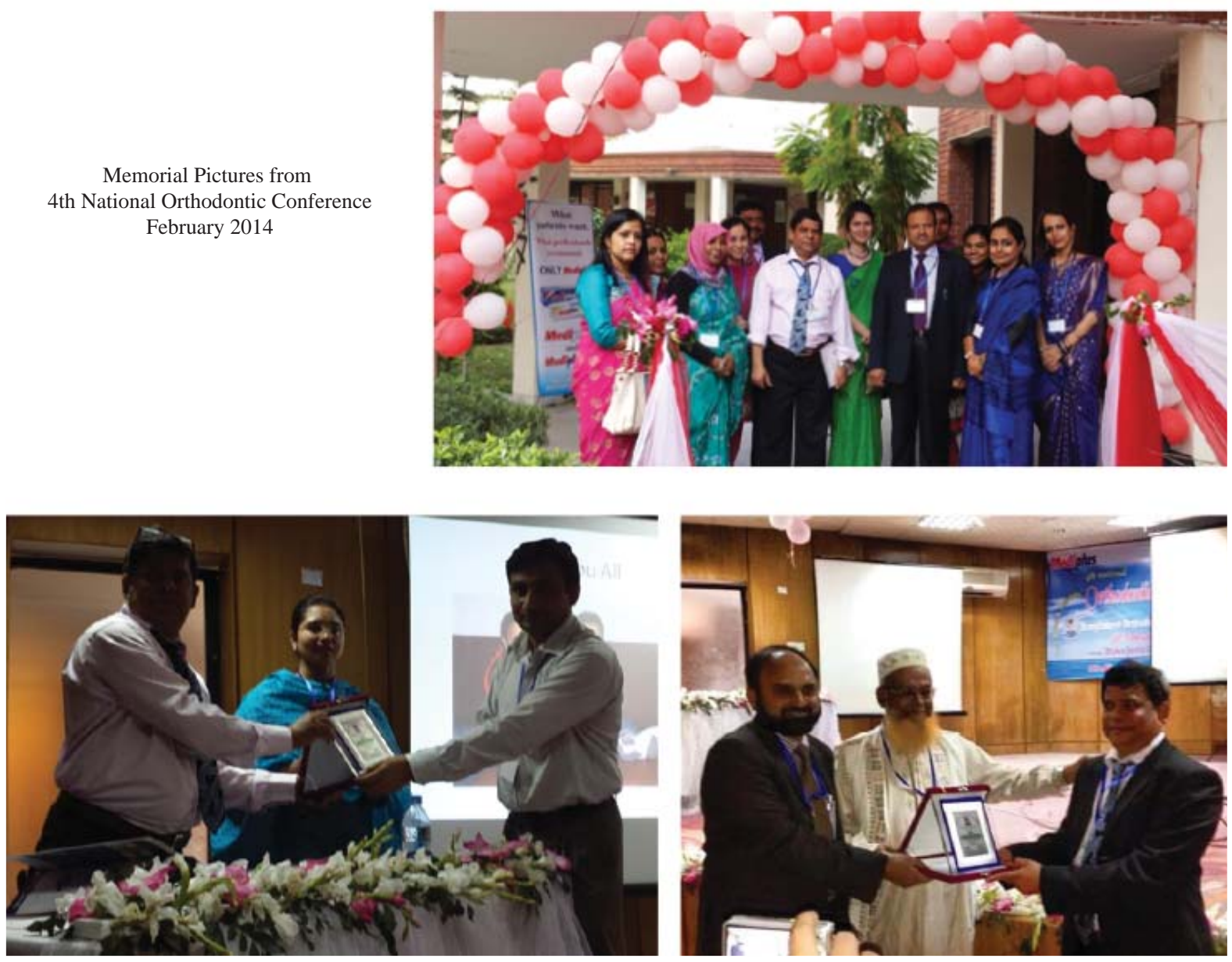